OPEN ACCESS

Edited by:

Girdhar Kumar Pandey,

University of Delhi, India

Reviewed by:

Nabil I. Elsheery,

Tanta University, Egypt

Lei Wang

Institute of Botany, China

${ }^{*}$ Correspondence:

Wei Wang

wangw@sdau.edu.cn

${ }^{\dagger}$ These authors have contributed equally to this work.

Specialty section:

This article was submitted to

Plant Physiology,

a section of the journal

Frontiers in Plant Science

Received: 09 November 2015

Accepted: 12 August 2016

Published: 05 September 2016

Citation:

Kong X, Zhou S, Yin S, Zhao Z,

Han $Y$ and Wang W (2016)

Stress-Inducible Expression of an

F-box Gene TaFBA1 from Wheat

Enhanced the Drought Tolerance

in Transgenic Tobacco Plants without

Impacting Growth and Development.

Front. Plant Sci. 7:1295.

doi: 10.3389/fpls.2016.01295

\section{Stress-Inducible Expression of an F-box Gene TaFBA1 from Wheat Enhanced the Drought Tolerance in Transgenic Tobacco Plants without Impacting Growth and Development}

\author{
Xiangzhu Kongt, Shumei Zhout, Suhong Yin, Zhongxian Zhao, Yangyang Han and \\ Wei Wang * \\ State Key Laboratory of Crop Biology, Shandong Key Laboratory of Crop Biology, College of Life Sciences, Shandong \\ Agricultural University, Tai'an, China
}

E3 ligase plays an important role in the response to many environment stresses in plants. In our previous study, constitutive overexpression of an F-box protein gene TaFBA1 driven by $35 S$ promoter improved the drought tolerance in transgenic tobacco plants, but the growth and development in transgenic plants was altered in normal conditions. In this study, we used stress-inducible promoter RD29A instead of $35 S$ promoter, as a results, the stress-inducible transgenic tobacco plants exhibit a similar phenotype with wild type (WT) plants. However, the drought tolerance of the transgenic plants with stress-inducible expressed TaFBA1 was enhanced. The improved drought tolerance of transgenic plants was indicated by their higher seed germination rate and survival rate, greater biomass and photosynthesis than those of WT under water stress, which may be related to their greater water retention capability and osmotic adjustment. Moreover, the transgenic plants accumulated less reactive oxygen species, kept lower MDA content and membrane leakage under water stress, which may be related to their higher levels of antioxidant enzyme activity and upregulated gene expression of some antioxidant enzymes. These results suggest that stress induced expression of TaFBA1 confers drought tolerance via the improved water retention and antioxidative compete ability. Meanwhile, this stress-inducible expression strategy by RD29A promoter can minimize the unexpectable effects by $35 S$ constitutive promoter on phenotypes of the transgenic plants.

Keywords: F-box, RD29A promoter, drought stress, water retention, antioxidative compete ability

\section{INTRODUCTION}

Abiotic stresses are the major limiting factors in plant growth and development, and can greatly affect crop production. Drought is one of the most common forms among abiotic stresses. Plants can response and adapt these stresses by many kinds of ways. For example, many genes may be up- or down- regulated to maintain the growth of plants under drought stress (Farooq et al., 2009). 
Meanwhile, lots of drought-related proteins accumulate to protect plants from the damage of deficit stress conditions $(\mathrm{Bu}$ et al., 2014). Although the responses of plants to drought are relatively widely considered, the molecular mechanisms of plant adaptation to drought are still fragmentary.

The ubiquitin-26S proteasome system (UPS) plays an important role in the resistance of plants to abiotic stress by affecting the stability of the cellular proteins (Perales et al., 2008; Stone, 2014). In the UPS, E3 acts as a central component in the ubiquitination process, which confirms the specificity to the target proteins (Dill et al., 2004). E3 ligase is a far more diverse group in plants. Among the E3 ligases, the SCF complex, named after the three key components Skp1, Cullin/CDC53 and F-box proteins, is essential in plants (Ciaffi et al., 2005). F-box protein, as a major subunit of the SCF complex, can bind to Skp1 through an F-box motif at the N-terminus of the protein, which consists of a 40-50 amino acid motif. The F-box protein recruits the targets via its C-terminus protein-protein interaction specificity to SCF E3. F-box proteins are involved in the response to biotic and abiotic stresses. DOR encodes an F-box protein in Arabidopsis, which functions as an inhibitor of ABA-induced stomatal closure under drought stress (Zhang et al., 2008). Overexpression of OsDRF1, a rice defense-related F-box protein gene, results in enhanced disease resistance against tomato mosaic virus (ToMV) and Pseudomonas syringae pv. Tabaci, and strengthens the sensibility to ABA in transgenic tobacco plants. TdRF1 is a durum wheat nuclear ubiquitin ligase, which can respond to cold and drought stress, and its homologous gene WVIP2 can negatively regulate the drought stress in Triticum durum (Guerra et al., 2012).

Drought stress may cause various adverse effects on plant growth and development, such as dwarf plant, smaller leaf area and decreased biomass. The maintenance of a high photosynthesis rate is a key factor for maintaining crop yields under stress conditions. Photosynthesis is sensitive to drought stress because water deficit results in the closing of stomata and decreases the internal leaf $\mathrm{CO}_{2}$ concentration (Dubey, 2005). Stress-induced changes are frequently related to an increase in membrane permeability, affecting membrane integrity and cell compartmentation under stress conditions. Reactive oxygen species (ROS)-mediated membrane injury involved in the membrane permeability during drought stress (Moore and Roberts, 1998).

In our previous study, we cloned an F-box protein gene from wheat (Zhou et al., 2014). The transgenic plants with overexpressed TaFBA1 under the control of the constitutive $35 S$ CaMV promoter displayed a changed phenotype in growth and development under normal conditions (Zhou et al., 2014). In the present study, the stress-inducible $R D 29 A$ promoter was used instead of $35 \mathrm{~S}$ promoter for TaFBA1 overexpression to minimize the effects on plant growth and development. Encouragingly, RD29A::TaFBA1 transgenic plants exhibited enhanced drought tolerance while avoiding the variation in the development process compared with 35S::TaFBA1 plants. We investigated the probable mechanism underlying the enhanced drought tolerance in the transgenic tobacco plants.

\section{MATERIALS AND METHODS}

\section{Ethics Statement}

This work did not involve endangered or protected species. We abided by the statement of ethical standards for submitted manuscripts, and the manuscript does not describe experiments involving human subjects or animals.

\section{Plant Materials, Growth Conditions, and Stress Conditions}

Transgenic tobacco (Nicotiana tabacum) lines containing the RD29A::TaFBA1 vector (RF-3, RF-4, RF-9), 35S::TaFBA1 vector (T3, T8) and wild type (WT) were used in this study. TaFBA1, an F-box gene, was isolated from wheat (Triticum aestivum L.; Zhou et al., 2014).

The tobacco seeds were sown in pots $(8 \mathrm{~cm} \times 10 \mathrm{~cm})$ containing vermiculite soaked with half-strength Hoagland nutrient solution in a growth chamber at $25^{\circ} \mathrm{C}$ with a $16 / 8 \mathrm{~h}$ (light/dark) cycle (300-400 $\mu \mathrm{mol}$ photons $\mathrm{m}^{-2} \mathrm{~s}^{-2}$ ) and relative humidity of $75-80 \%$.

For water stress treatment to seed germination, the transgenic and WT seeds were sown in a solution containing 0,10 or $20 \%$ PEG6000 (mass to volume ratio). For drought stress at the seedling stage, the transgenic and WT plants were germinated and grown under control growth conditions, and the water was withheld for a week to allow drought stress to develop. Then, these plants were rewatered and their growth was monitored after 3 days from rewatering.

For methyl viologen (MV) treatment, the transgenic and WT plants were sprayed with MV solution $(100 \mu \mathrm{M})$ every $6 \mathrm{~h}$ for three times and the phenotypic change was observed after $24 \mathrm{~h}$.

\section{RNA Extraction and cDNA Synthesis}

Total RNA was extracted from the tobacco leaves with the Trizol reagent (TaKaRa, Japan) according to the manufactures, protocol and was treated with DNaseI (RNase-free, Promega). The total RNA was subjected to first-strand cDNA synthesis with the RevertAid First Strand cDNA Synthesis Kit (Fermentas, USA) according to the manufacturer's protocol.

\section{Gene Expression Analysis by Quantitative Real-Time RT-PCR}

TaFBA1 expression was followed by the presence of a 222-bp fragment amplified with the primers QFBA1 and QFBA2. The Actin cDNA was used as a control. PCR was carried out in a final volume of $20 \mu \mathrm{l}$ containing $1 \times$ SYBR Green PCR MASTER Mix (TIANGEN, China), $500 \mathrm{nM}$ each primers and $120 \mathrm{fifth}$ of the RT reaction. Quantitative analysis was performed using the Bio Rad CFX Manager system with PCR conditions of $94^{\circ} \mathrm{C}$ for $20 \mathrm{~s}, 61^{\circ} \mathrm{C}$ for $30 \mathrm{~s}$ and $68^{\circ} \mathrm{C}$ for $35 \mathrm{~s}$ for 40 cycles. The absence of primer-dimer formation was confirmed using single and noprimer controls. Each sample was performed in triplicate using relative quantification analysis. Some primers of antioxidativerelated genes in tobacco were given in Table $\mathbf{1}$. 
TABLE 1 | Primer sequences were used in the article.

\begin{tabular}{llc}
\hline Name & Primer sequence $\mathbf{( 5}^{\prime} \mathbf{- 3}^{\prime} \mathbf{)}$ & Length (bp) \\
\hline Ntactin-F & CATTGGCGCTGAGAGATTCC & 20 \\
Ntactin-R & GCAGCTTCCATTCCGATCA & 19 \\
NtSOD-F & GACGGACCTTAGCAACAGG & 19 \\
NtSOD-R & CTGTAAGTAGTATGCATGTTC & 21 \\
NtRbohD-F & ACCAGCACTGACCAAAGAA & 19 \\
NtRbohD-R & TAGCATCACAACCACAACTA & 20 \\
NtCAT1-F & TGGATCTCATACTGGTCTCA & 20 \\
NtCAT1-R & TTCCATTGTTCAGTCATTCA & 21 \\
NtGPX-F & GGTTTGCACTCGCTTCAAG & 19 \\
NtGPX-R & AGTAGTGGCAAAACAGGAAG & 20 \\
NtAPX1-F & GAGAAATATGCTGCGGATGA & 20 \\
NtAPX1-R & CGTCTAATAACAGCTGCCAA & 20 \\
NtAPX2-F & GACAACTCATACTTACGGA & 20 \\
NtAPX2-R & CTTCAGCAAATCCCAACTCA & 20 \\
QFBA1 & AGCAGCAGAACAAGCCTGACCA & 22 \\
QFBA2 & ACGTGACGTTGGACAGCCTTG & 22 \\
\hline
\end{tabular}

\section{Western Blot Analysis}

Total protein was extracted from tobacco leaves in protein extraction buffer $(100 \mathrm{mM}$ Tris- $\mathrm{HCl}, \mathrm{pH}$ 8.0, $1 \%$ Polyvinylpyrrolidone, $10 \mathrm{mM} \quad \beta$-mercaptoethanol, $1 \mathrm{mM}$ EDTA-Na $2,0.2 \mathrm{M}$ sucrose) as described previously (Lee et al., 2007). Samples were centrifuged for $10 \mathrm{~min}$ at $4^{\circ} \mathrm{C}$, and supernatant containing soluble protein was harvested. Protein content was determined by the dye-binding assay according to Bradford (1976). Proteins were separated with SDS-PAGE on a $12 \%$ gradient gel and were electrophoretically transferred to polyvinylidene fluoride (PVDF) membranes (Millipore, Billerica, MA, USA). PVDF membranes were blocked for $2 \mathrm{~h}$ at room temperature in blocking buffer [11.25 mL Calf serum, $2.25 \mathrm{~g}$ Bovine Serum Albumin, and $63.75 \mathrm{~mL}$ phosphate buffered sodium (PBS)]. Next, membranes were incubated overnight at $4^{\circ} \mathrm{C}$ with TaFBA1 antibody diluted 1:1500 in blocking buffer. The coding region of TaFBA1 was integrated into the Pet-30a $(+)$ vector. Expression and purification of the recombinant TaFBA1 protein was processed using Ni-NTA agarose system. White mice were immunized by the purified recombinant protein to prepare antiserum, which was then purified to obtain the primary antibody aiming at TaFBA1 (Zhou et al., 2014). Membranes incubated with TaFBA1 antibody were washed three times for $15 \mathrm{~min}$ with PBS. Then, membranes were incubated for $3 \mathrm{~h}$ at room temperature with goat anti-mouse IgG, horseradish peroxidase conjugate (Santa Cruz Biotechnology, Santa Cruz, CA, USA) diluted 1:5000 in blocking buffer. Next, membranes were washed three times $15 \mathrm{~min}$ with PBS. Proteins were detected using chromogenic reagent $(0.6 \mathrm{~mL}$ methanol, $3 \mu \mathrm{L}$ $\mathrm{H}_{2} \mathrm{O}_{2}, 1.5 \mathrm{mg}$ 4-chloro-1-naphthol, and $5 \mathrm{~mL}$ PBS).

\section{Germination Rate Assay}

Seeds from WT and RD29A::TaFBA1 transgenic lines were sown on filter paper containing 0, 10 or 20\% PEG-6000 and cultured in an incubator $\left(16 \mathrm{~h} \mathrm{light} / 8 \mathrm{~h}\right.$ dark, $75 \%$ humidity, $\left.25^{\circ} \mathrm{C}\right)$. Germination rates were evaluated after 10 days.

\section{Measurement of Photosynthetic Gas Exchange and Chlorophyll Content}

The adult tobacco plants were used to estimate the photosynthetic rate $(\mathrm{Pn})$ with a portable photosynthetic system (CIRAS-2, PP Systems, Hitchin, UK). The measurements were carried out under the condition of a $\mathrm{CO}_{2}$ concentration of $360 \mu \mathrm{l}^{-1}$, PFD of $800 \mu \mathrm{mol} \mathrm{m}^{-2} \mathrm{~s}^{-1}$ and relative humidity of $60-70 \%$ and the temperature inside the leaf chamber was $25^{\circ} \mathrm{C}$. Before the assay, all tobacco plants were treated at $25^{\circ} \mathrm{C}, 100 \mu \mathrm{mol} \mathrm{m}^{-2} \mathrm{~s}^{-1} \mathrm{PDF}$ for at least $30 \mathrm{~min}$ to induce the stomata open, and then lighted at $800 \mu \mathrm{mol} \mathrm{m}^{-2} \mathrm{~s}^{-1} \mathrm{PDF}$ for $15 \mathrm{~min}$ to be acclimated.

The chlorophyll content assay was carried out according to Yang et al. (2009).

\section{Measurement of Water Loss, Relative Water Content, and Water Potential}

Measurement of water loss was carried out as Cheong et al. (2007). Relative water content (RWC) was calculated using the following equation $(\mathrm{FW}-\mathrm{DW}) /(\mathrm{TW}-\mathrm{DW}) \times 100 \%$. Meanwhile, FW is the fresh weight, TW is the saturated weight after soaking the samples in water for at least $12 \mathrm{~h}$ and DW is the dry weight after the shaping at $105^{\circ} \mathrm{C}$ for $15 \mathrm{~min}$ and then drying samples at $65^{\circ} \mathrm{C}$ for $24 \mathrm{~h}$. Water potential was measured with PS $\Psi \mathrm{PRO}^{\mathrm{TM}}$ water potential indicator (Wescor, USA) before and after drought treatment. Leaf disks from the third leaf were collected, immediately transferred to the chamber (C-52) which was equilibrated for 30 min before measurement. A stable instrument reading was obtained at that time.

\section{Determining of $\mathrm{H}_{2} \mathrm{O}_{2}$ content and $\mathrm{O}_{2}{ }^{-}$ Production Rate}

$\mathrm{H}_{2} \mathrm{O}_{2}$ content and $\mathrm{O}_{2}^{\bullet-}$ production rate was measured according to Li A.X. et al. (2014).

\section{Histochemical ROS Staining}

$\mathrm{H}_{2} \mathrm{O}_{2}$ and $\mathrm{O}_{2}{ }^{-}{ }^{-}$were detected by the $3,3^{\prime}$-diaminobenzidine (DAB) and nitrotetrazolium blue chloride (NBT) staining methods (Scarpeci et al., 2008; Zong et al., 2009). The seedlings were soaked in $5 \mathrm{mg} / \mathrm{ml} \mathrm{DAB}$ at $\mathrm{pH} 3.8$ for $20 \mathrm{~h}$ and $0.5 \mathrm{mg} / \mathrm{ml}$ NBT for $20 \mathrm{~h}$ in the dark condition to detect $\mathrm{H}_{2} \mathrm{O}_{2}$ and $\mathrm{O}_{2}{ }^{-}$, respectively. Then the seedlings were subsequently decolorized by boiling in ethanol (96\%) for $10 \mathrm{~min}$. After cooling, the seedlings were extracted at room temperature with $60 \%$ glycerol and photographed.

\section{Determining of Malondialdehyde (MDA) Content and Electrolyte Leakage}

Oxidative damage to lipids was estimates by measuring the content of MDA according to Quan et al. (2004). Electrolyte leakage was determined as described in Li A.X. et al. (2014).

\section{Extraction and Assay of Antioxidant Enzyme Activity}

Tobacco seedlings treated with drought stress were used for the determining of superoxide dismutase (SOD, EC 1.15.1.1), 
catalase (CAT, EC 1.11.1.6), and peroxidase (POD, EC 1.11.1.7) enzyme activities as described previously (Li A.X. et al., 2014). The glutathione reductase (GR), dehydroascorbate reductase (DHAR), and monodehydroascorbate reductase (MDHAR) activities were determined according to Li et al. (2011). Enzyme activity assays were carried out in a UV-vis spectrophotometer (UV-2550, Shimadzu, Japan) at $25^{\circ} \mathrm{C}$. The protein concentration of each enzyme extracts was determined according to the method of Bradford (1976).

\section{Statistical Analysis}

All experiments were repeated at least three times. Statistical analysis was conducted using the procedures of SPSS, and statistical significance was tested at a probability level of 0.01 and 0.05 .

\section{RESULTS}

\section{Generation and Identification of RD29A::TaFBA1 Transgenic Tobacco Plants}

In our previously study, the full-length cDNA of TaFBA1 gene was obtained from wheat (Zhou et al., 2014). Overexpression of TaFBA1 in transgenic tobacco led to an altered phenotype compared with WT under normal condition (Figure 1A). To eliminate the phenotypical variation, we cloned a water deficit stress-inducible $R D 29 A$ promoter from Arabidopsis, created a construct containing RD29A::TaFBA1, and transformed this construct into tobacco plants. TaFBA1 was successfully integrated into the tobacco genome (Figure 1B). Homozygous progeny of three transgenic lines RD29A::TaFBA1 (RF-3, RF-4, RF-9), 35S::TaFBA1(T3, T8) and WT tobacco plants were used. Stressinducible $R D 29 A$ promoter was induced by drought stress. Three-month-old plants were grown without watering for drought stress. TaFBA1 expression driven by $R D 29 A$ promoter was increased during drought stress treatment (Figure 1C). Furthermore, the expression of TaFBA1 at the protein level was confirmed by western blot analysis and the abundance of the TaFBA1 protein increased during drought stress treatment (Figure 1D), while the protein of WT was of no significant variety, which is similar to the result in Figure 1C.

\section{The Drought Tolerance of the Transgenic Tobacco Plants during Seed Germination and Seedling Growth}

Tobacco seeds of both WT and transgenic plants were sown in a solution containing 0, 10 or 20\% PEG6000 (Figure 2A). Under normal conditions, WT and transgenic plants had the similar germination rates. But the germination rate of transgenic plant seeds was higher than that of WT under stress conditions. In the presence of 10 and 20\% PEG6000, the germination rates of transgenic plants were approximately 90 and $60 \%$, while those of WT were 80 and 20\% (Figure 2B).

Wild type and transgenic lines were grown on soil for 2 weeks and then withdrawn water for 7 days. After the drought stress, we rewatered the plants for 3 days, and the survival rates were recorded (Figure 2C). The results showed that only $24.4 \%$ of WT were recovered from drought conditions after rewatering, while more than $70 \%$ of the transgenic plants survived (Figure 2D). These data suggest that the transgenic plants are less sensitive to drought stress compared with WT during seed germination and seedling stage.

\section{The Response of Growth and Photosynthesis of the Adult Transgenic Plants to Drought Stress}

Three-month-old plants were grown without watering for 15 days, and then rewatered for 3 days. The results showed that most of WT plants did not recover, while all three transgenic lines recovered and showed a vigorous growth status (Figure 3A). The biomass of transgenic plants was higher than these of WT (Figure 3B) when stressed for 15 days.

We also compared the photosynthetic indexes in the transgenic plants and WT under normal and drought conditions. Under normal condition, the photosynthetic rate (Pn) of transgenic tobacco lines was similar to that of WT. When suffering drought stress, Pn of transgenic plants was significantly higher than that of WT (Figure 3C), which is consistent with the phenotypic change (Figure 3A) and biomass (Figure 3B). The responses of chlorophyll content to drought stress in the transngenic lines and WT were consistent with photosynthetic rate (Figure 3D). The results in Figures 2 and $\mathbf{3}$ suggest that the RD29A::TaFBA1 transgenic tobacco plants had greater drought tolerance than WT plants.

\section{The RD29A::TaFBA1 Transgenic Plants Display a High Water Retention Capability}

We investigated the transpiration water loss and RWC in the transgenic plants and WT. The data in Figure 4A showed that there was no difference in RWC between WT and transgenic plants without stress, while the RWC level of transgenic plants was higher than that of WT when suffering drought stress. As shown in Figure 4B, the detached leaves of transgenic plants lost water more slowly than did those of WT. We also detected the relative expression level of TaFBA1 in the transgenic plants and WT under normal and water loss conditions. The expression of TaFBA1 was up-regulated in the transgenic plants under water loss conditions (Figure 4E).

In addition, transgenic plants exhibited lower osmotic potential than WT plants under water deficient conditions (Figure 4C). As transgenic plants had a lower osmotic potential, we determined the proline content of WT and transgenic plants. Drought stress induced a significant increase of proline content in both WT and transgenic tobacco lines, but the transgenic plants accumulated more proline compared with WT (Figure 4D).

\section{Transgenic Plants Accumulated Less ROS than WT under Water Stress}

Drought can induce the production and accumulation of ROS, which are toxic to plant cells. So we examined the levels of 

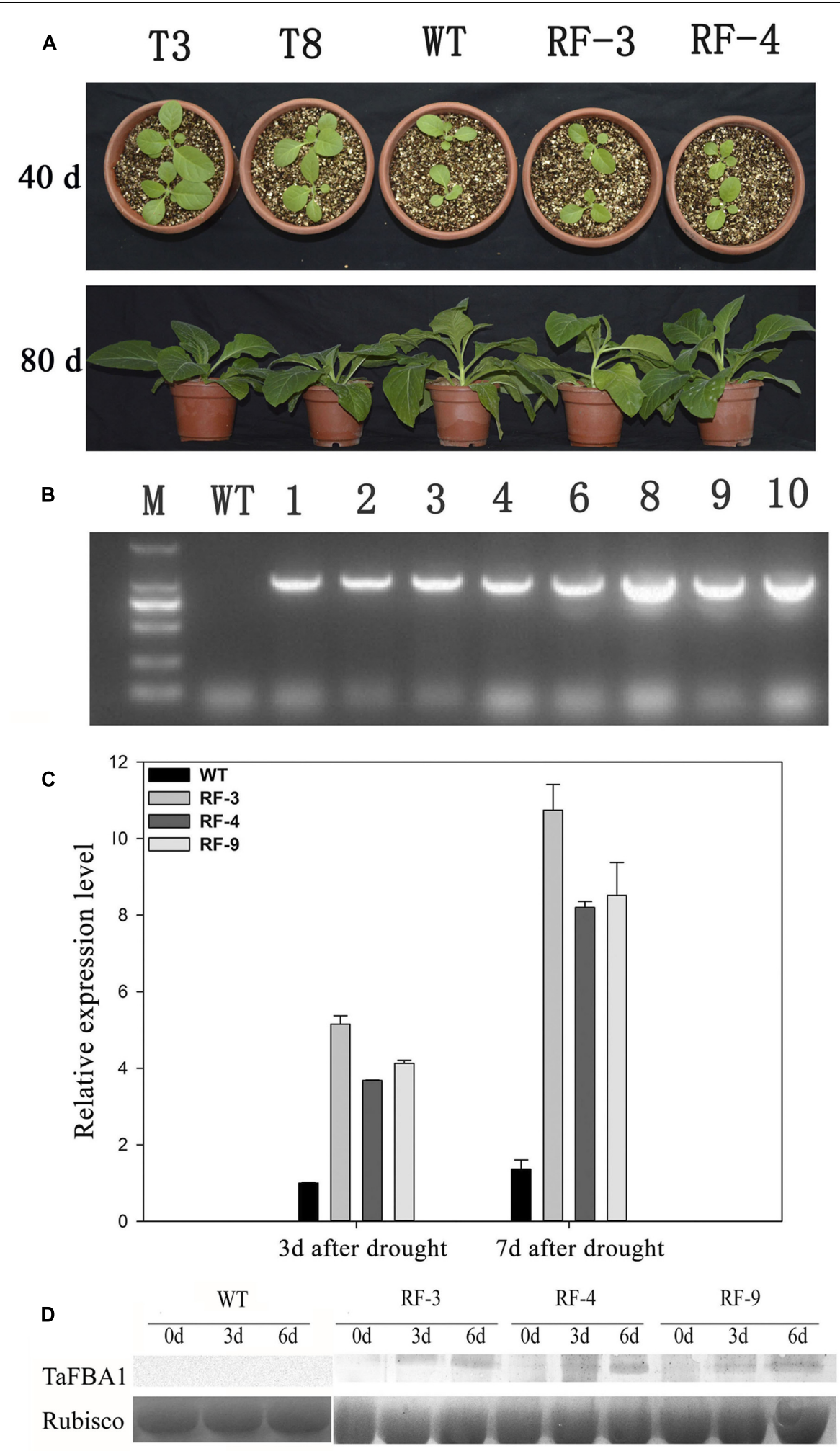

FIGURE 1 | Identification of RD29A::TaFBA1 transgenic tobacco lines. (A) Phenotype of 35S::TaFBA1 (T3, T8), RD29A::TaFBA1 (RF-3, RF-4) and WT plants at 40, 80 days after sowing. (B) Identification of RD29A::TaFBA1 transgenic tobacco lines by genome PCR. WT, wild-type; M, DNA marker. (C) Identification of RD29A::TaFBA1 transgenic plants by real-time RT-PCR. Three independent transgenic lines (RF-3, 4, and 9) were used. (D) TaFBA1 protein abundance in transgenic plants in different drought conditions, as revealed by western blot analysis, rubisco large subunit was used as a loading control. 
A

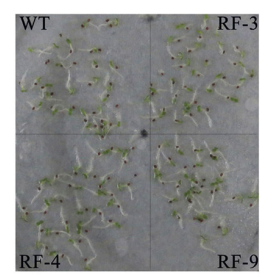

CK

C

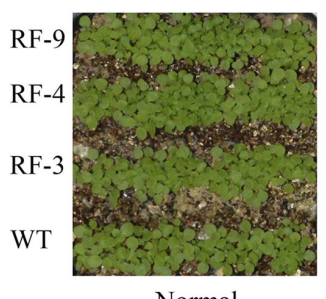

Normal

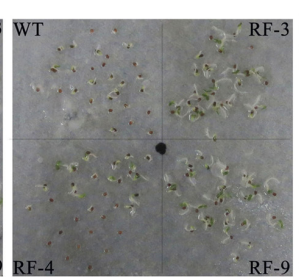

PEG10\%

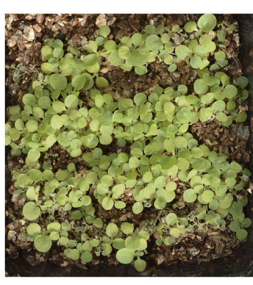

Treatment of drought

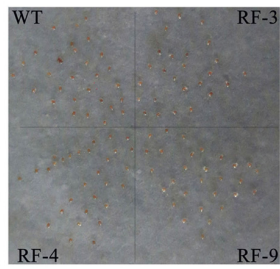

PEG20\%

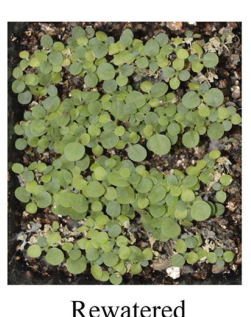

B

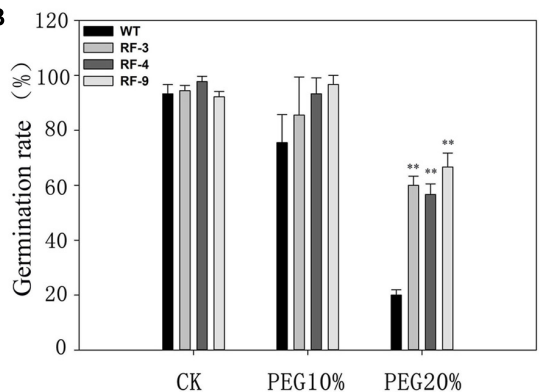

D

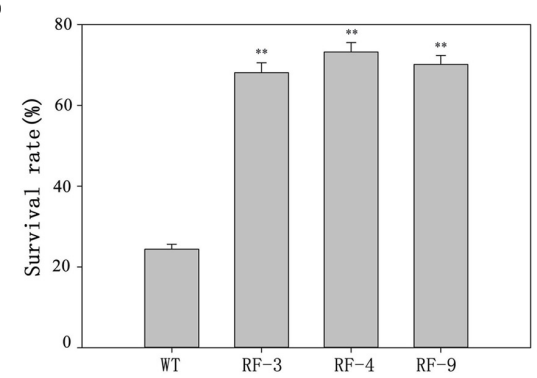

FIGURE 2 | The drought tolerance of transgenic tobacco seedlings with drought-inducible expression of TaFBA1 and WT. (A) Seed germination on filter paper containing 0 (CK), 15 and 20\% PEG6000. (B) Germination rate (\%) of RD29A::TaFBA1 and WT seeds in (A). Germination rate was scored every day and the final result at 7 days after germination was presented. (C,D) Survival rates of transgenic and WT plants after withholding water for 10 days (Treatment of drought) and then rehydration for 3 days (Rewatered). The survival rate was scored according to the rewatered plants. The experiments were repeated three times. Each column represents the average of at least three replicates \pm standard error (SE). "** and "**" indicates significant differences compared with WT at $P<0.05$ and $P<0.01$.

endogenous hydrogen peroxide $\left(\mathrm{H}_{2} \mathrm{O}_{2}\right)$ and superoxide radical $\left(\mathrm{O}_{2}^{\bullet-}\right)$ by $\mathrm{DAB}$ and $\left.\mathrm{NBT}\right)$ staining. The WT plant leaves were more strongly stained with DAB and NBT than transgenic plant leaves under water stress (Figure 5A).

We also measured the $\mathrm{H}_{2} \mathrm{O}_{2}$ content and $\mathrm{O}_{2}{ }^{-}-$production rates in the leaves. As the results of DAB and NBT staining assays, drought stress induced the accumulation of $\mathrm{H}_{2} \mathrm{O}_{2}$ levels and $\mathrm{O}_{2}^{\bullet}-$ production in the plant leaves examined. However, the levels of $\mathrm{H}_{2} \mathrm{O}_{2}$ and $\mathrm{O}_{2}^{\bullet}$ - were nearly 2 - and 1.5-fold higher in WT plant, respectively, compared with those in the transgenic plants (Figures 5B,C).

Under drought conditions, plenty of ROS is produced in plant, which can induce membrane lipid peroxidation leading to an increase of the membrane permeability (Farooq et al., 2009). Then, we measured the electrolyte leakage of the transgenic plants under drought conditions. No significant difference was found between transgenic and WT plants without drought stress, but drought stress induced higher electrolyte leakage in WT plants compared with the transgenic lines (Figure 5E).

MDA content is usually considered as an index of membrane lipid peroxidation. Drought stress enhanced MDA contents of both transgenic and WT plants, whereas the MDA content was significantly lower in transgenic plants compared with WT plants under drought stress (Figure 5D).

Methylviologen (MV) can induce plant cells to produce excessive superoxide anions, which have a toxic effect on plant cells. Therefore, we observed the effects of MV treatment on the phenotypes of both WT and transgenic plants. From
Figure 5F, no difference was observed between WT and transgenic lines under normal water conditions, but when exposed to MV (10 $\mu \mathrm{M})$, WT plants exhibited a severely inhibited phenotype, while the transgenic plants displayed a higher tolerance to MV (Figure 5F), and this is further proved by the chlorophyll contents (Figure 5G). The results in Figure 5 suggested that TaFBA1 expression can decrease the ROS accumulation to protect tobacco from oxidative damage, and transgenic plants were less damaged by MV compared with WT.

\section{The Transgenic Plants have High Antioxidant Enzyme Activity}

As less ROS was detected in transgenic plants (Figure 5), we measured the activities of some antioxidant enzymes, which can reduce the ROS accumulation in plants. The data in Figure 6 indicated that the activities of POD, CAT and APX were all significantly increased when treated with drought stress, but the activities of them in transgenic plants were higher than WT. As an exception, the activity of SOD was decreased when suffered to drought stress. However, the SOD activity was still much higher in transgenic plants than that of WT, which was similar to POD, CAT, and APX (Figure 6A).

Glutathione reductase, DHAR, and MDHAR are key enzymes of the ASA-GSH cycle, which are related to eliminate $\mathrm{H}_{2} \mathrm{O}_{2}$ and $\mathrm{O}_{2}^{\bullet}-$ (Noctor and Foyer, 1998). We next measured the activities of them. Under drought condition, the GR activity of transgenic plants was higher by about 1.5 -fold than that of WT, while 
A
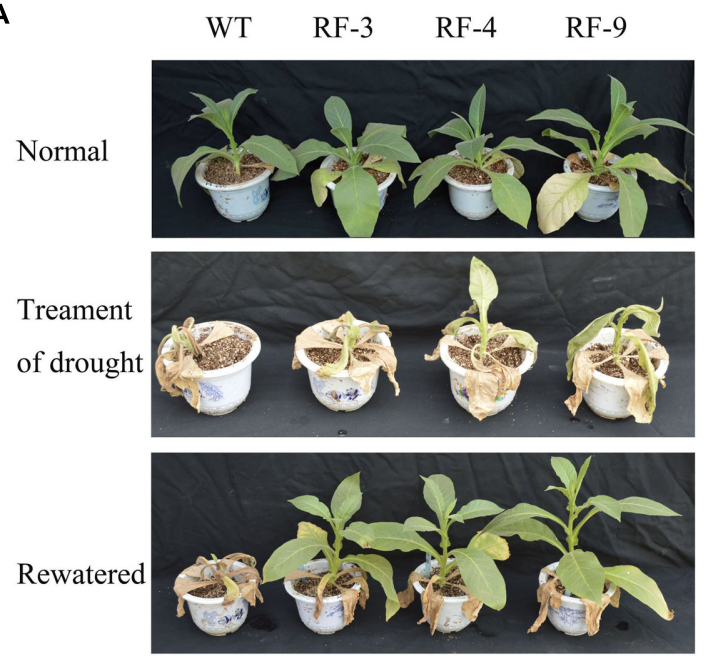

C

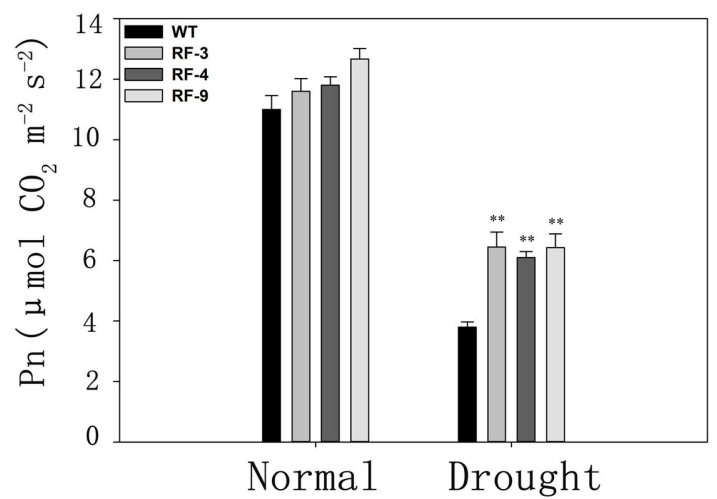

B

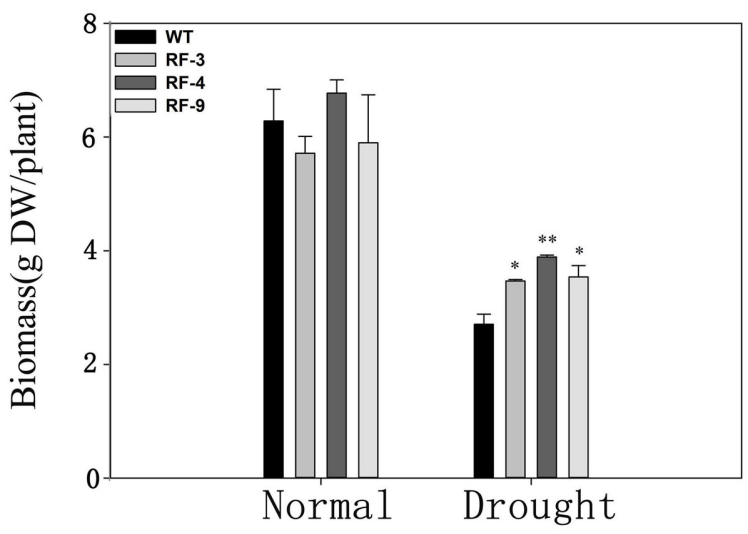

D

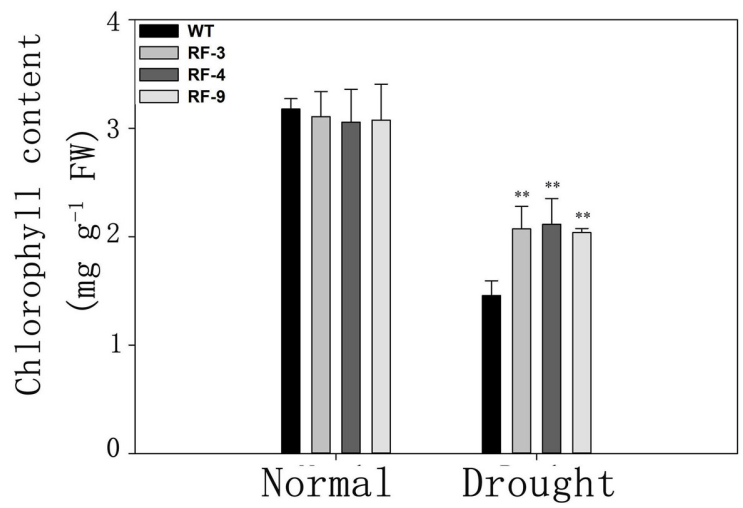

FIGURE 3 | Physiological characteristics of adult transgenic and WT plants in response to drought stress. (A) Phenotype of transgenic and WT plants after withholding water for 15 days (Treatment of drought) and then rehydration for 3 days (Rewatered) in the greenhouse. (B) Overground biomass of each individual plant. Plants were cultivated in soil for 75 days. DW, dry weight. (C) Net photosynthetic rate (Pn). (D) The chlorophyll content of all lines after drought treatment. Each column represents the average of at least three replicates \pm standard error (SE). "*" and "**" indicates significant differences compared with WT at $P<0.05$ and $P<0.01$

the activities of DHAR and MDHAR had no obvious difference between WT and transgenic plants under drought conditions.

Together, the results in Figures 5 and $\mathbf{6}$ suggested that the enhanced tolerance to oxidative stress in transgenic plants may be due to the increase of antioxidant enzyme activity.

\section{TaFBA1 Overexpression Induced the Expression of Some Antioxidant-Related Genes}

To investigate the mechanisms of the oxidant tolerance in transgenic plants during drought conditions, gene expression levels were analyzed quantitatively after the tobacco plants had been subjected to drought stress for a week. We analyzed the expression of NtSOD, NtCAT, NtGPX, NtRbhoD, NtAPX1, $N t A P X 2$, which have been reported to enhance the oxidant tolerance in tobacco (Slooten et al., 1995). As shown in Figure 7 , drought treatment up-regulated the expression of some antioxidant- related genes, including NtCAT, NtGPX, NtRbhoD, NtAPX1, NtAPX2, whereas the expression of NtSOD was decreased after drought stress treatment. Above all, the expression of these genes in transgenic plants was all higher than that in WT plants, which was similar to the change of antioxidant enzyme activity (Figure 6).

\section{DISCUSSION}

\section{Expressing TaFBA1 Driven by RD29A instead of $35 S$ Promoter Eliminates its Impact on the Phenotype of Transgenic Plants}

Promoter plays a decisive role in the gene expression. Transgenic plants are usually created with a functional gene under the control of the constitutive CaMV $35 S$ promoter. The constitutive 
A

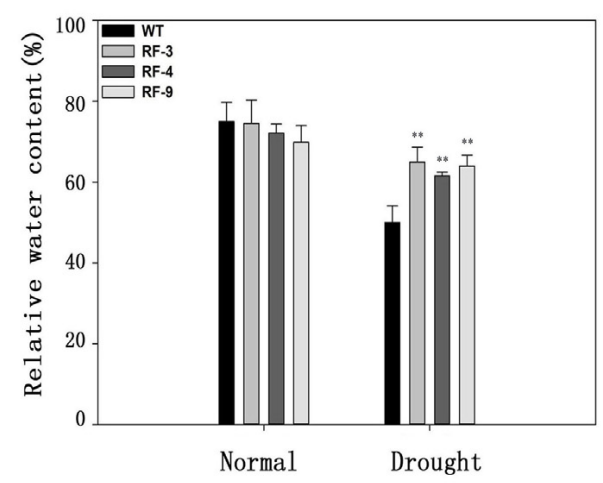

C

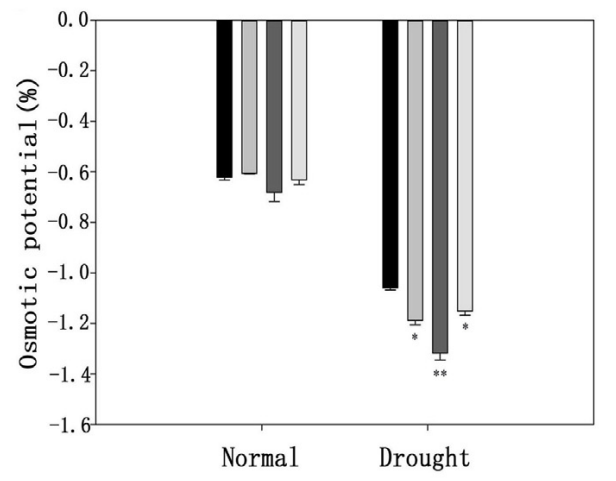

B

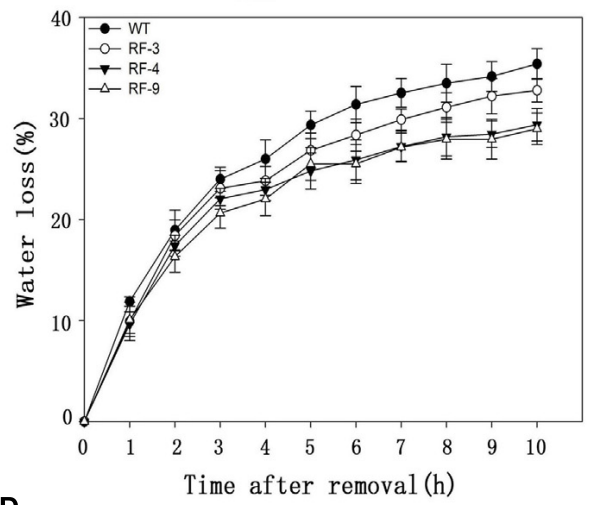

D

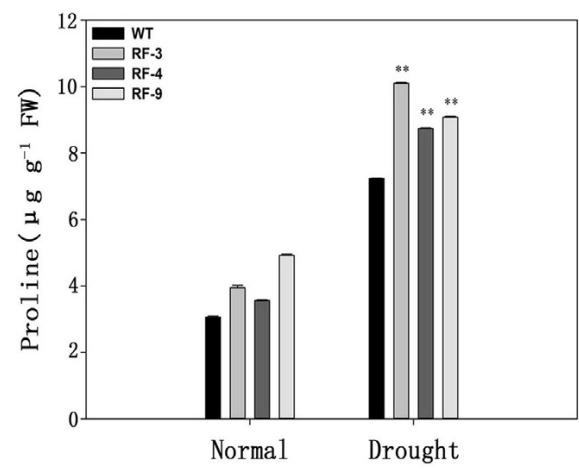

$\mathbf{E}$

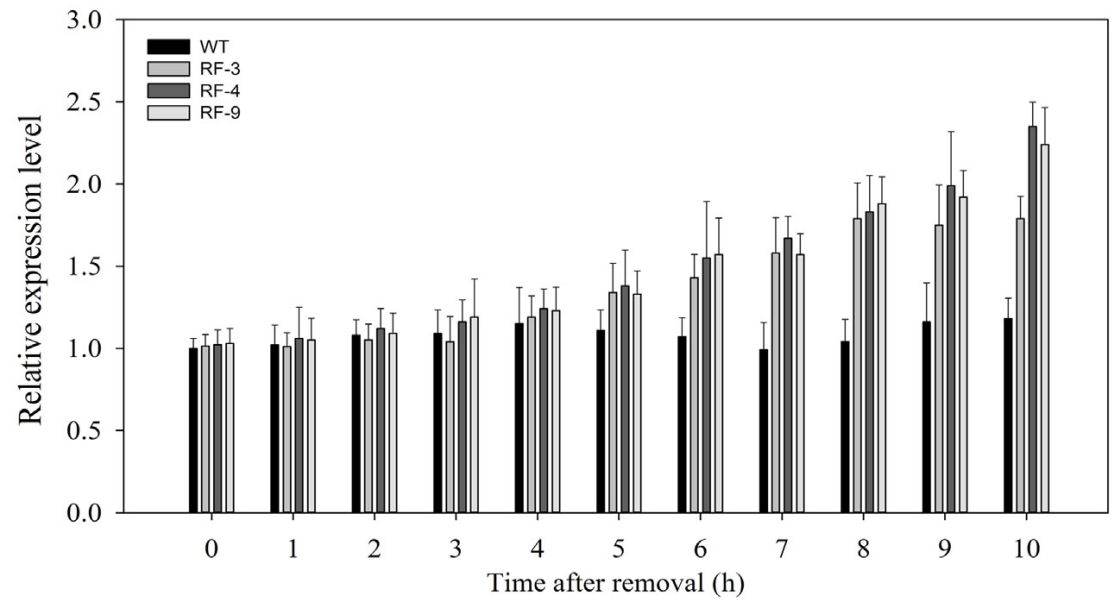

FIGURE 4 | The response of relative water content (RWC), water loss, osmotic potential, proline content and expression of TaFBA1 in WT and transgenic plants. (A) RWC of tobacco leaves after drought stress. (B) Kinetics of water loss from the leaves of 50-day-old tobacco plants. (C) Osmotic potential of tobacco leaves. (D) Proline content in WT and transgenic plant leaves. (E) Relative expression level of TaFBA1 from the leaves of 50-day-old tobacco plants after removal. Each column represents the average of at least three replicates \pm standard error (SE). "*" and "**" indicates significant differences compared with WT at $P<0.05$ and $P<0.01$.

promoter leads to the expression of target genes in all tissues and organs of plants at all developmental stages, which usually influences the growth and development of transgenic plants (Jaglo-Ottosen et al., 1998; Gilmour et al., 2000). So the novel promoter that directs gene expression only in relevant stress is essential. In previous studies, the use of $R D 29 A$ promoter showed more benefits than that of CaMV $35 S$ (Yamaguchi-Shinozaki and Shinozaki, 1993; Kasuga et al., 2004; Pellegrineschi et al., 2004). RD29A contains dehydration responsive element (DRE) and can be stress-inducible. It allows low expression levels of target genes under normal conditions and a rapid increase of the genes when suffering dehydration stress (Yamaguchi-Shinozaki and Shinozaki, 1994). In our previous study, TaFBA1 gene controlled by $35 S$ promoter was transformed into tobacco and 
A

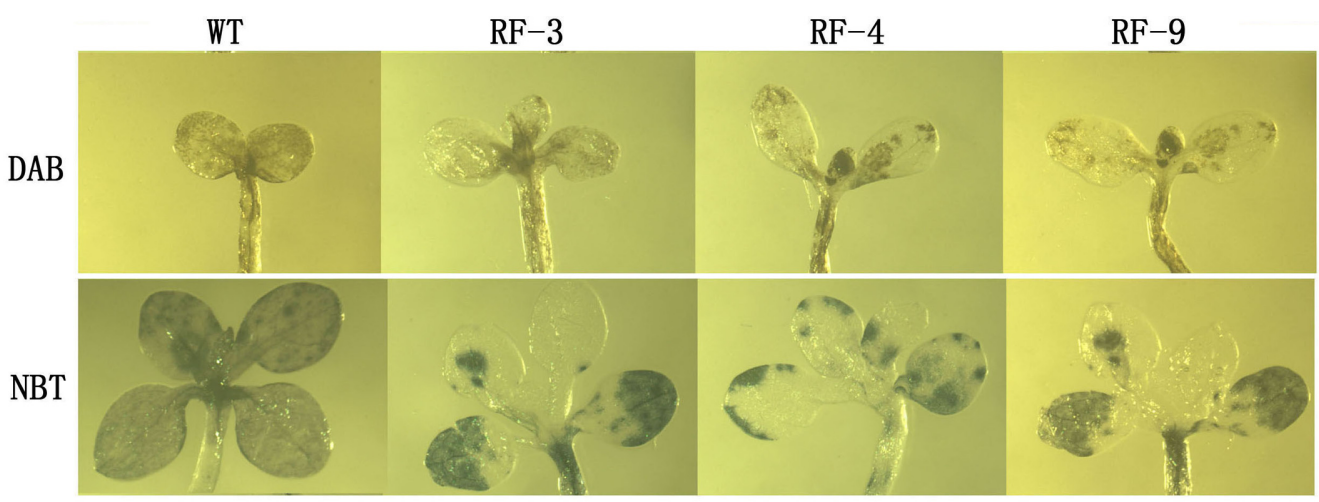

B

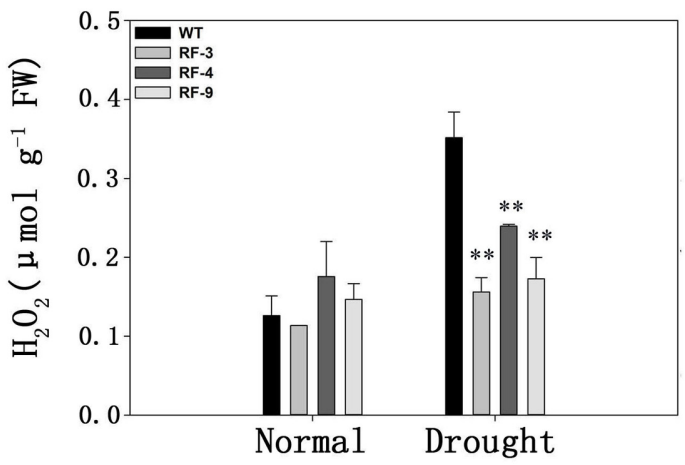

D

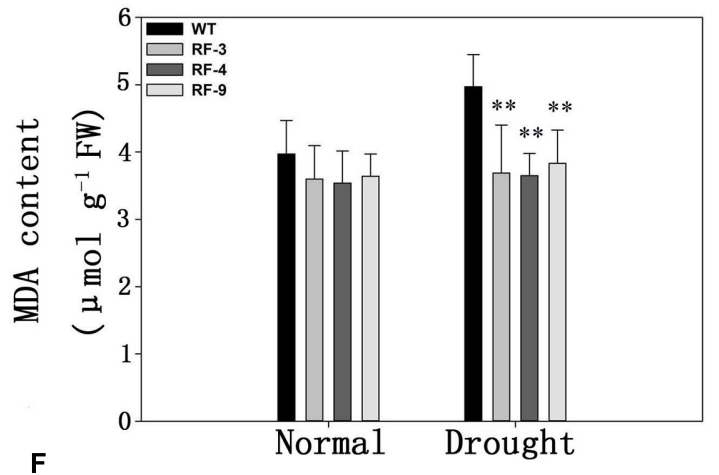

$\mathbf{F}$

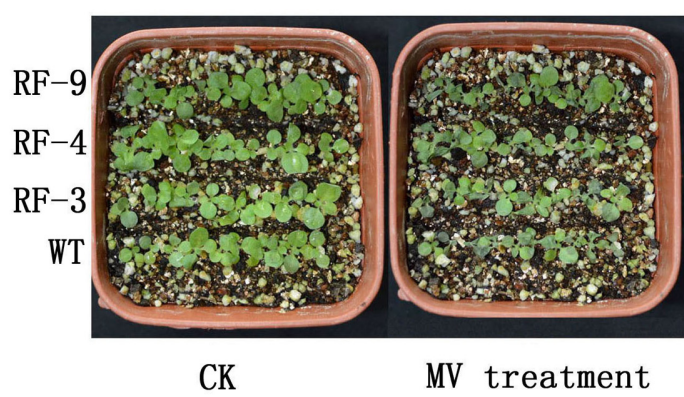

C

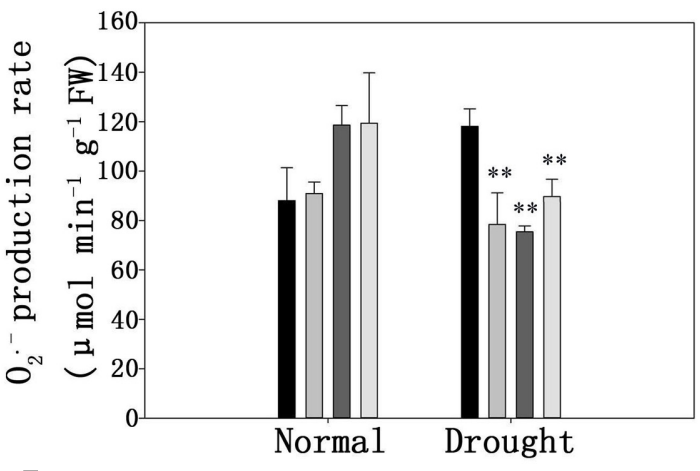

E

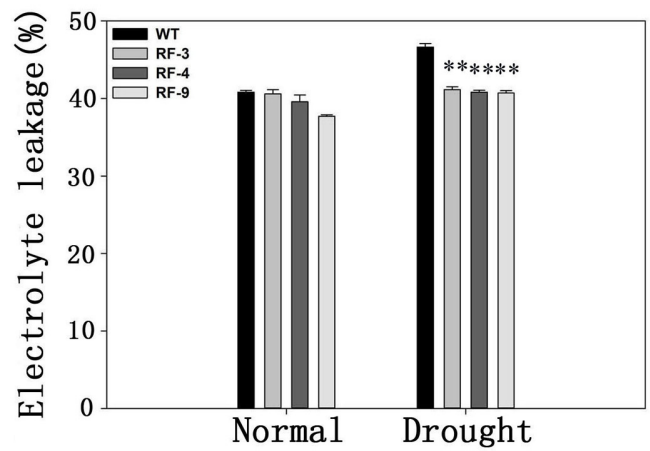

G

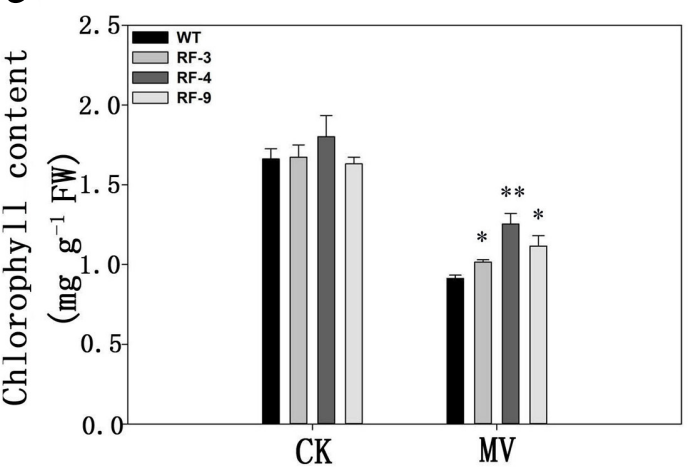

FIGURE 5 | Analysis of ROS accumulation and oxidative damage in WT and transgenic plants under water stress. (A) In situ detection of $\mathrm{H}_{2} \mathrm{O}_{2}$ and $\mathrm{O}_{2}^{\bullet}$ by DAB and NBT staining of WT and transgenic seedlings grown on normal medium for a week and then treated with 200 mM mannitol for 10 days. (B-E) $\mathrm{H}_{2} \mathrm{O}_{2}$ content, $\mathrm{O}_{2}^{\bullet}$ - production rate, MDA content and the electrolyte leakage of 60-day-old WT and transgenic plants treated with $20 \%$ PEG6000 for 3 days.

(F) Phenotype of 2-week-old seedlings of MV treatments for $24 \mathrm{~h}$. (G) Chlorophyll content of the seedlings in (F). Each column represents the average of at least three replicates \pm standard error (SE). "*" and "**" indicates significant differences compared with WT at $P<0.05$ and $P<0.01$. 
A

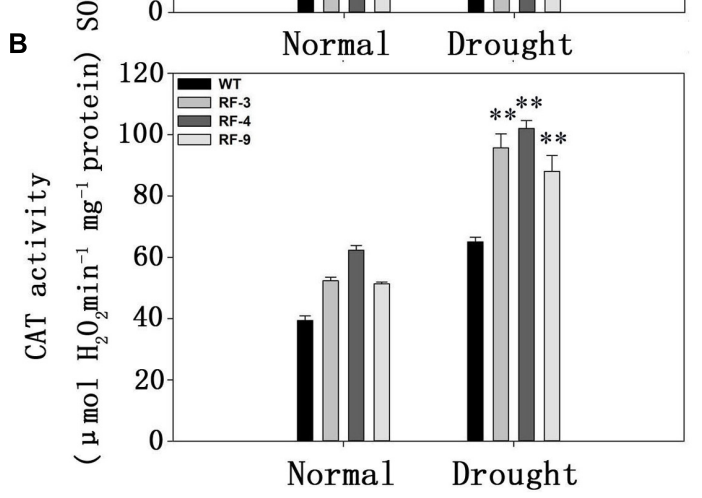

C
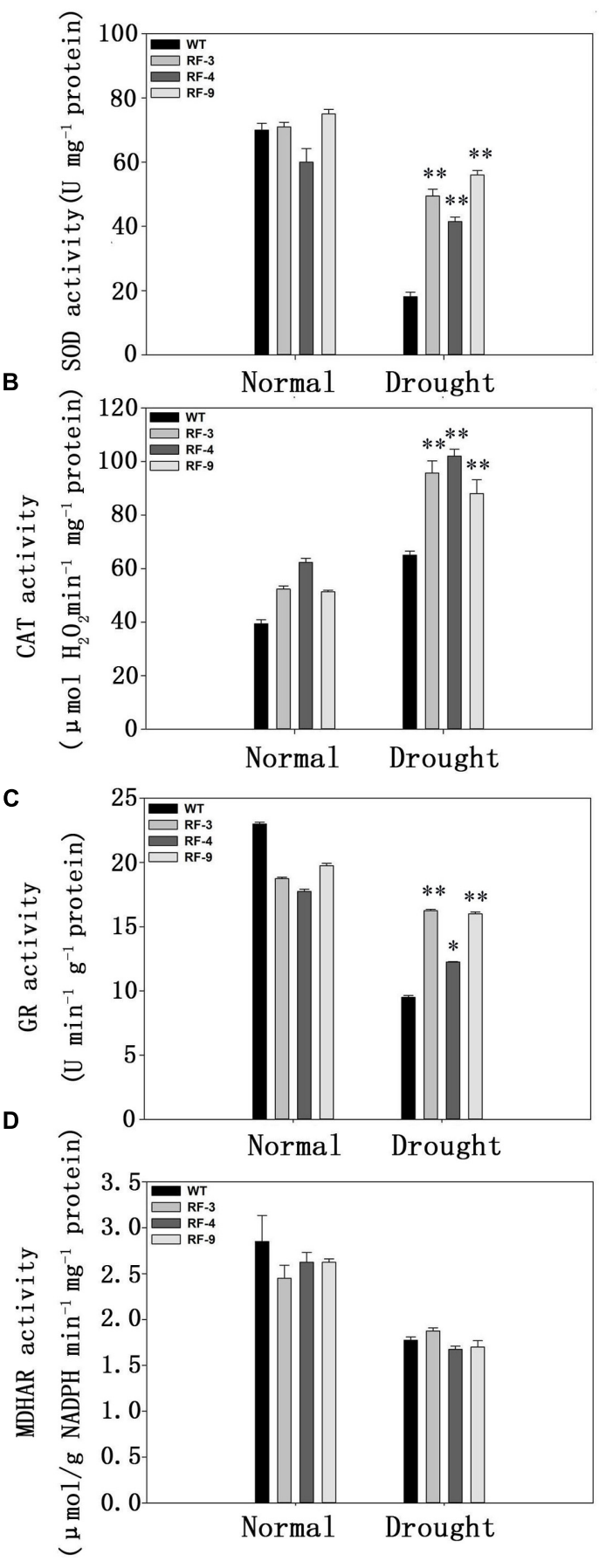

E

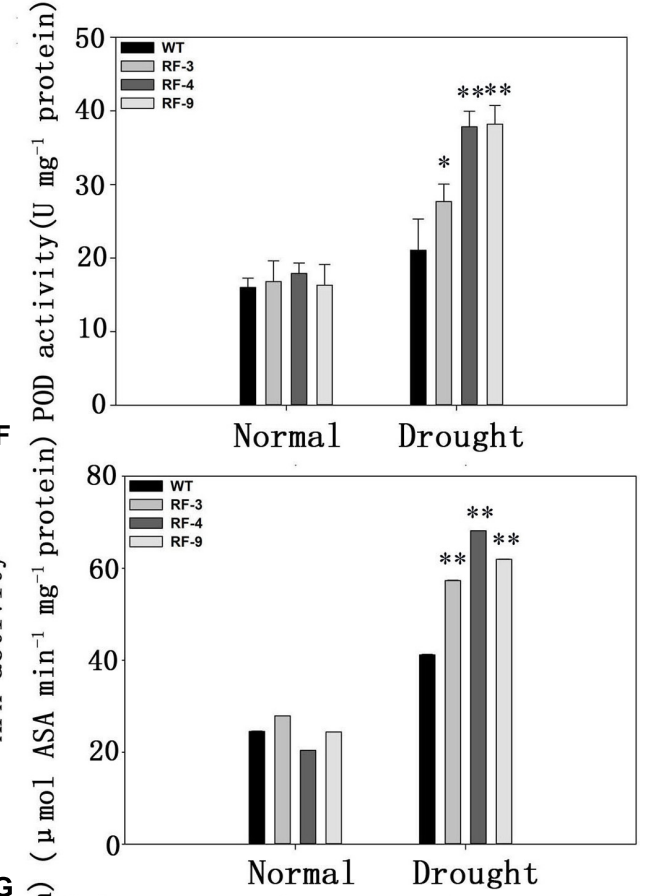

$\mathbf{G}$

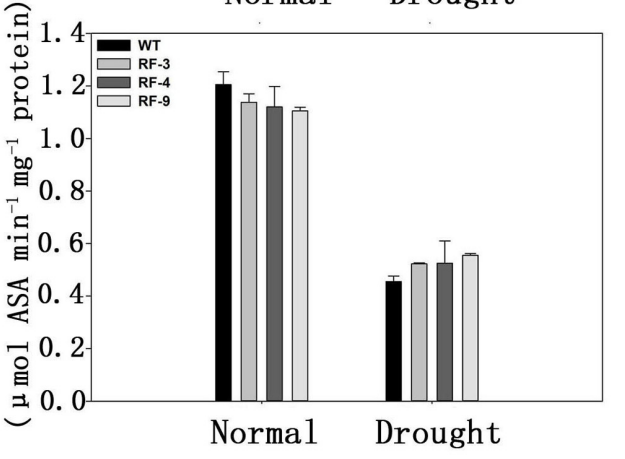

FIGURE 6 | The activities of the antioxidant enzymes in WT and transgenic plants under drought stress. (A) SOD, superoxidase dismutase; (B) POD, guaiacol peroxidase; (C) CAT, catalase; (D) APX, ascorbate peroxidase; (E) GR, glutathione reductase; (F) DHAR, dehydroascorbate reductase; (G) MDHAR, monodehydroascorbate reductase. Each column represents the average of at least three replicates \pm standard error (SE). "*" and "**" indicates significant differences compared with WT at $P<0.05$ and $P<0.01$.

some transgenic plants were obtained (Zhou et al., 2014). But we found that the phenotype of transgenic plants was much different from that of WT under normal water conditions (Figure 1A). To eliminate this diversity, stress-inducible promoter was used to generate transgenic tobacco plants with overexpression of TaFBA1 (Figure 1B). Under normal condition without stress, the transformed gene was no expression, but drought stress induced its mRNA and TaFBA1 accumulation rapidly (Figures $\mathbf{1 C}, \mathbf{D}$ ). 

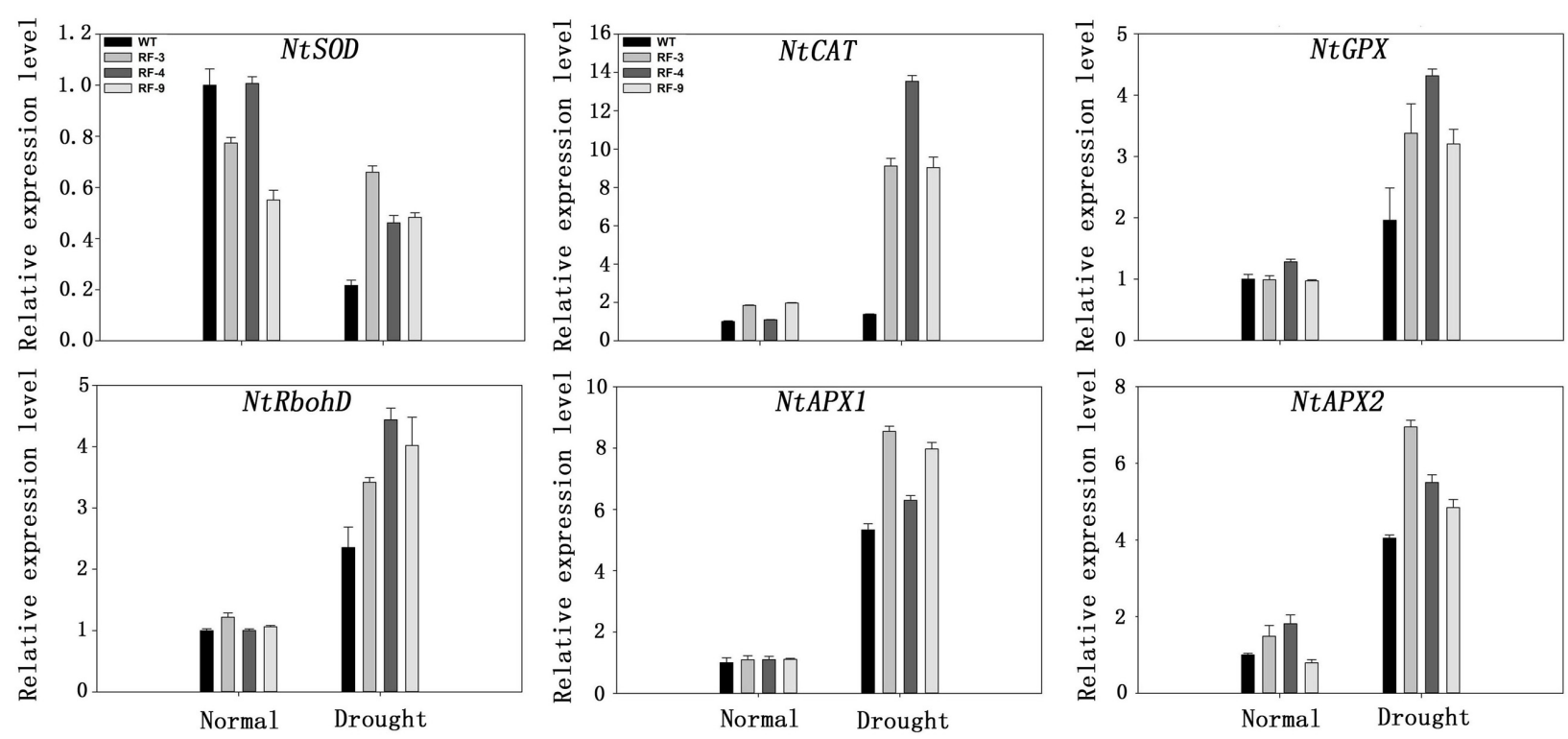

FIGURE 7 | Expression of antioxidant related genes in WT and transgenic plants under drought stress by real-time RT-PCR. Transcript levels of these genes in transgenic plants are indicated relative to the levels in WT plants (set at 1), referring to the transcript of actin in the same samples. Each column represents the average of at least three replicates \pm standard error (SE).

We found that the growth and developmental patterns of the RD29A transgenic plants were similar to that of WT under normal conditions (Figure 1A). In the following experiments, the RD29A transgenic tobacco lines, RF-3, RF-4, and RF-9 were used to examine their drought stress tolerance.

\section{Drought-Inducible Expression of TaFBA1 Confers Drought Tolerance in Transgenic Plants}

For most plants, seed germination and early seedling growth are highly sensitive to the abiotic stresses (Mito et al., 2010). Previous studies have also revealed that F-box genes play important roles in seed germination (Jia et al., 2011; Rajjou et al., 2012; Li Y.Z. et al., 2014). In Figure 2, under normal condition, no significant difference in germination and seedling growth was found between the transgenic lines and WT. But the transgenic lines showed a better germination and growth, and a higher survival rate than WT under drought stress. When exposed to drought conditions, the phenotype and physiological observations of the grown transgenic plants were also superior compared with these of WT (Figures 3A,B).

Stomata is one of the first induction in plants to drought stress, and drought can lead to the closure of stomata, which can limit the gas exchange between the cell and atmosphere and will cause the reduction in photosynthesis (Farooq et al., 2009; Bhargava and Sawant, 2013). Drought stress can also influence the stability of thylakoid membrane to depress the photosynthesis of plants (Chaves et al., 2009). The Pn of transgenic plants was higher than WT when suffering drought stress (Figure 3C). This may related to the higher chlorophyll content in transgenic plants (Figure 3D).

\section{Transgenic Plants Remain High Water Content by Decreasing of the Osmotic Potential}

Drought is one of the most common factors of abiotic stresses, which is usually due to the continuous water loss through transpiration and evaporation into atmosphere and less water taken from the soil (Bhargava and Sawant, 2013; Koffler et al., 2014). Drought resistance can be due to the drought avoidance via more water retention and less water loss. From Figures 4A,B, the transgenic tobacco plants have a high water content and low water loss.

Osmotic regulation ability also participates in the water conservation. When plants are exposed to drought stress, they actively accumulate solutes and, as a result, $\Psi_{\mathrm{s}}$ drop, promoting the flow of water into the cell (Chaves et al., 2009). Proline, as a common solute, can be used as index of osmotic adjustment in plants. From Figure 4D, the proline contents were higher in transgenic plants than that of WT when suffering drought stress, which may contribute to the low osmotic potential in transgenic lines (Figure 4C). All these data suggest that expression of TaFBA1 confers drought tolerance in transgenic tobacco. Transgenic plants remain high water content may be by decreasing of the osmotic potential via accumulating of some solutes such as proline.

\section{The Expression of TaFBA1 Results Low ROS Accumulation under Drought Conditions}

Drought stress usually results in stomatal closure. The stomatal closure caused by drought stress limits $\mathrm{CO}_{2}$ uptake by leaves, 
leading to the exhaustion of the primary electron acceptor NADP and the block of the electron transport to NADP, which contributes to the formation of relative oxygen species (ROS; Foyer and Noctor, 2009; Miller et al., 2010; Koffler et al., 2014). Excess production of ROS destroys the cellular structures and the metabolism in plants (Bartels and Sunkar, 2005). The TaFBA1 transgenic plants accumulated less ROS contents than WT under drought condition (Figures 5A-C).

The cell membrane is the main target in the process of oxidative damage induced by drought stress. Therefore, cell membrane stability is commonly used as an index of stress tolerance (Yue et al., 2011). MDA is the final product of lipid peroxidation and is usually used as an index of the level of membrane damage (Moore and Roberts, 1998). Electrolyte leakage, MDA content in both transgenic and WT plants increased under drought stress, while those of transgenic plants were lower than WT (Figures 5D,E), suggesting that the transgenic plants have a weaker membrane damage caused by ROS than WT under drought stress.

As a secondary stress, oxidative stress is extensive in most abiotic stresses (Dinakar et al., 2012). Plants own antioxidant systems keeping the ROS at a steady level to protect plants from oxidant damage. Some antioxidant enzymes, such as SOD, POD, CAT and APX, are involved in this process. The activities of all the antioxidant enzymes in the transgenic plants were higher significantly compared to that of WT under drought stress (Figures 6A-D). The higher mRNA levels of antioxidant genes in transgenic plants under drought stress may be involved in the enhanced activities of antioxidant enzymes in transgenic plants (Figure 7).

The ascorbate-glutathione (ASA-GSH) cycle, a nonenzymatic antioxidant defense systems, is also involved in removing the excess of ROS. GR, DHAR and MDHAR, key enzymes of the cycle, play an important role in the non-enzymatic

\section{REFERENCES}

Bartels, D., and Sunkar, R. (2005). Drought and salt tolerance in plants. Crit. Rev. Plant Sci. 24, 23-58. doi: 10.1080/07352680590910410

Bhargava, S., and Sawant, K. (2013). Drought stress adaptation: metabolic adjustment and regulation of gene expression. Plant Breed. 132, 21-32. doi: $10.1111 /$ pbr.12004

Bradford, M. M. (1976). A rapid and sensitive method for the quantitation of microgram quantities of protein utilizing the principle of protein-dye binding. Anal. Biochem. 72, 248-254. doi: 10.1016/0003-2697(76)90527-3

Bu, Q., Lv, T., Shen, H., Luong, P., Wang, J., Wang, Z., et al. (2014). Regulation of drought tolerance by the F-box protein MAX2 in Arabidopsis. Plant Physiol. 164, 424-439. doi: 10.1104/pp.113.226837

Chaves, M. M., Flexas, J., and Pinheiro, C. (2009). Photosynthesis under drought and salt stress: regulation mechanisms from whole plant to cell. Ann. Bot. 103, 551-560. doi: 10.1093/aob/mcn 125

Cheong, Y. H., Pandey, G. K., Grant, J. J., Batistic, O., Li, L., Kim, B. G., et al. (2007). Two calcineurin B-like calcium sensors interacting with protein kinase CIPK23, regulate leaf transpiration and root potassium uptake in Arabidopsis. Plant J. 52, 223-239. doi: 10.1111/j.1365-313X.2007.03236.x

Ciaffi, M., Paolacci, A. R., D’Aloisio, E., Tanzarella, O. A., and Porceddu, E. (2005). Identification and characterization of gene sequences expressed in wheat spikelets at the heading stage. Gene 346, 221-230. doi: 10.1016/ j.gene.2004.11.004 system (Hoque et al., 2007). GR, DHAR, and MDHAR activities were higher in transgenic plants than in the WT (Figures 6E-G), suggesting the possible involvement of glutathione cycle in the defense of oxidant damage. All these revealed that plants can protect themselves from oxidant stress caused by drought stress by both enzymatic and non-enzymatic antioxidant defense systems.

\section{CONCLUSION}

Our results suggest that the expression of TaFBA1 driven by $R D 29 A$ promoter in tobacco can confers enhanced tolerance to drought stress, probably first by keeping high water retention and low osmotic potential, then by scavenging the excrescent ROS and decreasing the oxidative damage, while no significant difference in phenotype between WT and transgenic plants under normal water conditions. Meanwhile, our results will be useful to elucidate the function of the F-box gene in plant abiotic stress responses.

\section{AUTHOR CONTRIBUTIONS}

Conceived and designed the experiments: SZ, WW. Performed the experiments: XK, SZ, SY, ZZ. Analyzed the data: XK, SZ, YH. Contributed reagents/materials/analysis tools: SZ, WW. Wrote the paper: XK, SZ. Proof read and final approval: SZ, WW.

\section{FUNDING}

This study was supported by the National Natural Science Foundation of China (No. 31370304) and by the Natural Science Foundation of Shandong Province, China (No. ZR2015CL037).

Dill, A., Thomas, S. G., Hu, J. H., Steber, C. M., and Sun, T. P. (2004). The Arabidopsis F-Box protein SLEEPY1 targets gibberellin signaling repressors for gibberellin-induced degradation. Plant Cell 16, 1392-1405. doi: 10.1105/tpc.020958

Dinakar, C., Djilianov, D., and Bartels, D. (2012). Photosynthesis in desiccation tolerant plants: energy metabolism and antioxidative stress defense. Plant Sci. 182, 29-41. doi: 10.1016/j.plantsci.2011.01.018

Dubey, R. S. (2005). "Photosynthesis in plants under stressful conditions," in Handbook of Photosynthesis, 2nd Edn, ed. M. Pessarakli (New York, NY: CRC Press), 717-737.

Farooq, M., Wahid, A., Kobayashi, N., Fujita, D., and Basra, S. M. A. (2009). Plant drought stress: effects, mechanisms and management. Agron. Sustain. Dev. 29, 153-188. doi: 10.1051/agro:2008021

Foyer, C. H., and Noctor, G. (2009). Redox regulation in photosynthetic organisms: signaling, acclimation, and practical implications. Antioxid. Redox Signal. 11, 861-905. doi: 10.1089/ars.2008.2177

Gilmour, S. J., Sebolt, A. M., Salazar, M. P., Everard, J. D., and Thomashow, M. F. (2000). Overexpression of the Arabidopsis CBF3 transcriptional activator mimics multiple biochemical changes associated with cold acclimation. Plant Physiol. 124, 1854-1865. doi: 10.1104/pp.124.4.1854

Guerra, D., Mastrangelo, A. M., Lopez-Torrejon, G., Marzin, S., and Schweizer, P. (2012). Identification of a protein network interacting with TdRF1, a wheat RING ubiquitin ligase with a protective role against cellular dehydration. Plant Physiol. 158, 777-789. 
Hoque, M. A., Banu, M., Okuma, E., Amako, K., Nakamura, Y., Shimoishi, Y., et al. (2007). Exogenous proline and glycinebetaine increase $\mathrm{NaCl}$-induced ascorbate-glutathione cycle enzyme activities, and proline improves salt tolerance more than glycinebetaine in tobacco Bright Yellow-2 suspensioncultured cells. J. Plant Physiol. 164, 1457-1468. doi: 10.1016/j.jplph.2006.10.004

Jaglo-Ottosen, K. R., Gilmour, S. J., Zarka, D. G., Schabenberger, O., and Thomashow, M. F. (1998). Arabidopsis CBF1 overexpression induces COR genes and enhances freezing tolerance. Science 280, 104-106. doi: 10.1126/science.280.5360.104

Jia, Y., Gu, H., Wang, X., Chen, Q., Shi, S., Zhang, J., et al. (2011). Molecular cloning and characterization of an F-box family gene CarF-box1 from chickpea (Cicer arietinum L.). Mol. Biol. Rep. 39, 2337-2345. doi: 10.1007/s11033-011-0984-y

Kasuga, M., Miura, S., Shinozaki, K., and Yamaguchi-Shinozaki, K. (2004). A combination of the Arabidopsis DREB1A gene and stress inducible Rd29A promoter improved drought- and low temperature stress tolerance in tobacco by gene transfer. Plant Cell Physiol. 45, 346-350. doi: 10.1093/pcp/pch037

Koffler, B. E., Luschin-Ebengreuth, N., Stabentheiner, E., Müller, M., and Zechmann, B. (2014). Compartment specific response of antioxidants to drought stress in Arabidopsis. Plant Sci. 227, 133-144. doi: 10.1016/ j.plantsci.2014.08.002

Lee, D. G., Ahsan, N., Lee, S. H., Kang, K. Y., Lee, J. J., and Lee, B. H. (2007). An approach to identify cold-induced low-abundant proteins in rice leaf. C. R. Biol. 330, 215-225. doi: 10.1016/j.crvi.2007.01.001

Li, A. X., Han, Y. Y., Wang, X., Chen, Y. H., Zhao, M. R., Zhou, S. M., et al. (2014). Root-specific expression of wheat expansin gene TaEXPB23 enhances root growth and water stress tolerance in tobacco. Environ. Exp. Bot. 110, 73-84. doi: 10.1016/j.envexpbot.2014.10.002

Li, Q., Yu, B., Gao, Y., Dai, A. H., and Bai, J. G. (2011). Cinnamic acid pretreatment mitigates chilling stress of cucumber leaves through altering antioxidant enzyme activity. J. Plant Physiol. 168, 927-934. doi: 10.1016/j.jplph.2010.11.025

Li, Y. Z., Jia, F. J., Yu, N. L., Luo, L., Huang, J. G., Yang, G. D., et al. (2014). The SCF E3 ligase AtPP2-B11 plays a negative role in response to drought stress in Arabidopsis. Plant Mol. Biol. Rep. 32, 943-956. doi: 10.1007/s11105-014-0705-5

Miller, G., Suzuki, N., Ciftci-Yilmaz, S., and Mittler, R. (2010). Reactive oxygen species homeo-stasis and signalling during drought and salinity stresses. Plant Cell Environ. 33, 453-467. doi: 10.1111/j.1365-3040.2009.02041.x

Mito, T., Seki, M., and Shinozaki, K. (2010). Generation of chimeric repressors that confer salt tolerance in Arabidopsis and rice. Plant Biotechnol. J. 9, 736-746. doi: 10.1111/j.1467-7652.2010.00578.x

Moore, K., and Roberts, L. J. (1998). Measurement of lipid peroxidation. Free Radic. Res. 28, 659-671. doi: 10.3109/10715769809065821

Noctor, G., and Foyer, C. H. (1998). Ascorbate and glutathione: keeping active oxygen under control. Annu. Rev. Plant Physiol. Plant Mol. Biol. 49, 249-279. doi: 10.1146/annurev.arplant.49.1.249

Pellegrineschi, A., Reynolds, M., Pacheco, M., Maria, B. R., Almeraya, R., Yamaguchi-Shinozaki, K., et al. (2004). Stress-induced expression in wheat of the Arabidopsis thaliana DREB1A gene delays water stress symptoms under greenhouse conditions. Genome 47, 493-500. doi: 10.1139/g03-140

Perales, L., Peñarrubia, L., and Cornejo, M. J. (2008). Induction of a polyubiquitin gene promoter by dehydration stresses in transformed rice cells. J. Plant Physiol. 165, 159-171. doi: 10.1016/j.jplph.2006.12.012
Quan, R., Shang, M., Zhang, H., Zhao, Y., and Zhang, J. (2004). Improved chilling tolerance by transformation with betA gene for the enhancement of glycinebetaine synthesis in maize. Plant Sci. 166, 141-149. doi: 10.1016/ j.plantsci.2003.08.018

Rajjou, L., Duval, M., Gallardo, K., Catusse, J., Bally, J., Job, C., et al. (2012). Seed germination and vigor. Ann. Rev. Plant. Biol. 63, 507-533.

Scarpeci, T. E., Zanor, M. I., Carrillo, N., Mueller-Roeber, B., and Valle, E. M. (2008). Generation of superoxide anion in chloroplasts of Arabidopsis thaliana during active photosynthesis: a focus on rapidly induced genes. Plant Mol. Biol. 66, 361-378. doi: 10.1007/s11103-007-9274-4

Slooten, L., Capiau, K., Van Camp, W., Van Montagu, M., Sybesma, C., and Inzé, D. (1995). Factors affecting the enhancement of oxidative stress tolerance in transgenic tobacco overexpressing manganese superoxide dismutase in the chloroplasts. Plant Physiol. 107, 737-750.

Stone, S. L. (2014). The role of ubiquitin and the $26 \mathrm{~S}$ proteasome in plant abiotic stress signaling. Front. Plant Sci. 5:135. doi: 10.3389/fpls.2014.00135

Yamaguchi-Shinozaki, K., and Shinozaki, K. (1993). Arabidopsis DNA encoding two desiccation responsive rd29 genes. Plant Physiol. 101, 1119-1120. doi: 10.1104/pp.101.3.1119

Yamaguchi-Shinozaki, K., and Shinozaki, K. (1994). A novel cis-acting element in an Arabidopsis gene is involved in responsiveness to drought, low-temperature or high-salt stress. Plant Cell 6, 251-264. doi: 10.2307/3869643

Yang, Q., Chen, Z. Z., Zhou, X. F., Yin, H. B., Li, X., Xin, X. F., et al. (2009). Overexpression of SOS (salt overly sensitive) genes increases salt tolerance in transgenic Arabidopsis. Mol. Plant 2, 22-31. doi: 10.1093/mp/ssn058

Yue, Y. S., Zhang, M. C., Zhang, J. C., Duan, L. S., and Li, Z. H. (2011). Arabidopsis LOS5/ABA3 overexpression in transgenic tobacco (Nicotiana tabacum cv. Xanthi-nc) results in enhanced drought tolerance. Plant Sci. 181, 405-411. doi: 10.1016/j.plantsci.2011.06.010

Zhang, Y., Xu, W., Li, Z., Deng, X., Wu, W., and Xue, Y. (2008). F-box protein DOR functions as a novel inhibitory factor for abscisic acid-induced stomatal closure under drought stress in Arabidopsis. Plant Physiol. 148, 2121-2133. doi: 10.1104/pp.108.126912

Zhou, S., Sun, X., Yin, S., Kong, X., Zhou, S., Xu, Y., et al. (2014). The role of the F-box gene TaFBA1 from wheat (Triticum aestivum L.) in drought tolerance. Plant Physiol. Biochem. 84, 213-223. doi: 10.1016/j.plaphy.2014.09.017

Zong, X. J., Li, D. P., Gu, L. K., Li, D. Q., Liu, L. X., and Hu, X. L. (2009). Abscisic acid and hydrogen peroxide induce a novel maize group C MAP kinase gene, $\mathrm{ZmMPK} 7$, which is responsible for the removal of reactive oxygen species. Planta 229, 485-495. doi: 10.1007/s00425-008-0848-4

Conflict of Interest Statement: The authors declare that the research was conducted in the absence of any commercial or financial relationships that could be construed as a potential conflict of interest.

Copyright (c) 2016 Kong, Zhou, Yin, Zhao, Han and Wang. This is an open-access article distributed under the terms of the Creative Commons Attribution License (CC BY). The use, distribution or reproduction in other forums is permitted, provided the original author(s) or licensor are credited and that the original publication in this journal is cited, in accordance with accepted academic practice. No use, distribution or reproduction is permitted which does not comply with these terms. 